\title{
Incidental detection of two adult gravid filarial worms in breast: a case report
}

\author{
Santosh Tummidi* ${ }^{*}$, Kanchan Kothari, Roshni Patil, Shruti S. Singhal and Pooja Keshan
}

\begin{abstract}
Background: Microfilaria is a major public health problem in tropical and subtropical countries and is an endemic problem in India. Wuchereria bancrofti is the commonest filarial infection. In some lesions, microfilariae and adult filarial worm have been incidentally detected in fine-needle aspirates.

Case presentation: A 35 year old hindu female presented with lump in upper outer quadrant of left breast. Fine needle aspiration revealed two adult gravid female filarial worms.

Conclusion: To our knowledge this is the first ever case report to demonstrate two live gravid female and embryoid forms in wet mount preparation.
\end{abstract}

Keywords: Adult gravid worm, Embryoid forms, Filaria, Breast, Fine needle aspiration

\section{Background}

Filariasis has been a disabling parasitic disease worldwide, particularly in tropical and sub-tropical countries of the world. The disease is fairly endemic in India. The commonest causative agents are two closely related nematodes, Wuchereria bancrofti and Brugia malayi accounting for $98 \%$ of cases. Human beings serve as definitive host for the parasite while culex mosquitoes serve as the intermediate host $[1,2]$. It has predilection for lower limbs, spermatic cord and epididymis while breast, thyroid, body fluids and skin are unusual sites [3-5]. Despite the fact that large numbers of people are at risk and wide varieties of tissues are affected, adult worm is rarely found in fine-needle aspiration cytology (FNAC) smears. Till date there are only 4 cases demonstrating adult female worm in breast lump aspirates.

\section{Case presentation}

A 35 year old hindu female came with complaints of lump in the left breast since 3 years with pain since 4 days. On examination, a lump was present in upper outer quadrant of left breast measuring $1 \times 1 \mathrm{~cm}$ (Fig. 1A). There was

\footnotetext{
*Correspondence: born_vss@yahoo.co.in Department of Pathology, Seth GSMC \& KEMH, Parel, Mumbai, Maharashtra 4900012, India
}

no axillary lymphadenopathy and contralateral breast was normal. She had no history of fever/trauma/nipple discharge/variation in size of lump. All hematological parameters were normal except for mild anemia. Bilateral sonomammography revealed cystic lesion measuring $1 \times 0.7 \mathrm{~cm}$ containing multiple curvilinear echoes, with "filarial dance" in the subcutaneous plane of left breast, at around 2 o'clock position (Fig. 1B). She was then referred for cytology diagnosis of the lump.

FNA from the lump was done using $23 \mathrm{gz}$ needles. During the procedure, we were able to aspirate two adult filarial gravid female worms along with $2 \mathrm{ml}$ of granular turbid material. The worms were put on a plain slide and measured to be 3 and $4.5 \mathrm{~cm}$ respectively (Fig. 1C, D). Wet mount preparation of the parasite was done using normal saline. Microscopy showed two adult female worms, one with intact head and tail ends while other was incomplete. The worm was then given a nick in intestinal region from where embryoid forms of the parasite were seen to release out in thousands (Fig. 2A-C) (Additional file 1: Video 1). Smears were then stained with Toluidine blue, Papanicoloau and Geimsa. Microscopy revealed adult gravid female worm with many embryoid forms as well as coiled and uncoiled sheathed microfilariae with tail end being free of nuclei. A granulomatous reaction along with few lymphocytes, polymorphs 


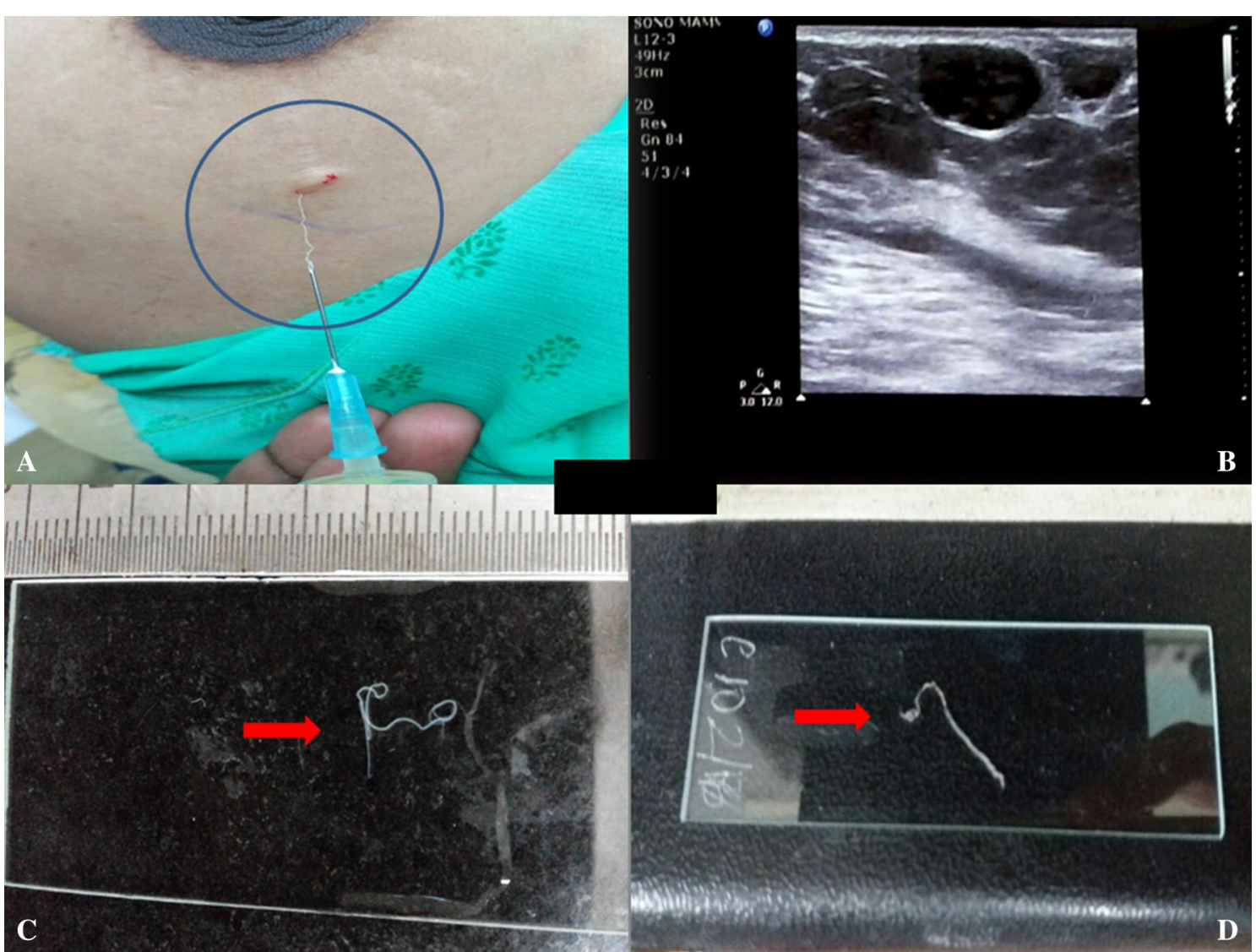

Fig. 1 A Aspiration of the parasite from lump in the upper outer quadrant of left breast; B sonomammography with cystic lesion measuring $1 \times 0.73 \mathrm{~cm}$ and filarial dance sign; C adult filarial female worm on slide after 1st attempt of fine needle aspiration; $\mathbf{D}$ another adult filaria worm on 2nd attempt of fine needle aspiration

and histiocytes was also seen (Figs. 2D, E, 3A-E). Cytological diagnosis was given as breast filariasis due to $W$. bancrofti. One of the adult worms was also processed for histopathology and revealed similar features (Fig. 3F).

\section{Discussion}

The medical literature documents filariasis back to 600 BC when Sustruta recognized the clinical manifestation of elephantiasis and referred it as elephantiasis arabicum [3]. These nematodes belong to the order Spirurida and superfamily Filarioidia [1]. Adult worms are found in lymphatic vessels of lower limbs, spermatic cord, epididymis, testis, retroperitoneum and breast of humans, while the larval forms (microfilaria) may circulate in the peripheral blood [4]. The adult female worms are usually of $80-100 \mathrm{~mm}$ length, ovoviviparous giving birth to ova containing microfilariae whereas males are $40 \mathrm{~mm}$ in length [1].
The clinical spectrum of lymphatic filariasis ranges from only peripheral blood eosinophilia to lymphangitis finally terminating in elephantiasis. The parasite is usually found in lymphatics sometimes causing obstruction with cystic change. The probable explanation for the mechanism of microfilariae reaching extravascular tissue spaces from microcirculation is by crossing the vessel wall by their boring ability [5].

Although there are reports of accidental detection of microfilaria using aspiration cytology in various sites like spermatic cord [6], epididymis [6], testis, lymph nodes [7], retroperitoneum, soft tissue, breast [3] and bone marrow etc. [5], reports of adult worms in cytological aspirates are sparse. Pandit et al. [8] and Azad et al. [9] reported the presence of adult filarial worms in soft tissue swellings. Satpathi et al. [10], Pal et al. [11], Chakarbarti et al. [3] and Naorem et al. [12] have reported cases of adult filarial worms in the breast 


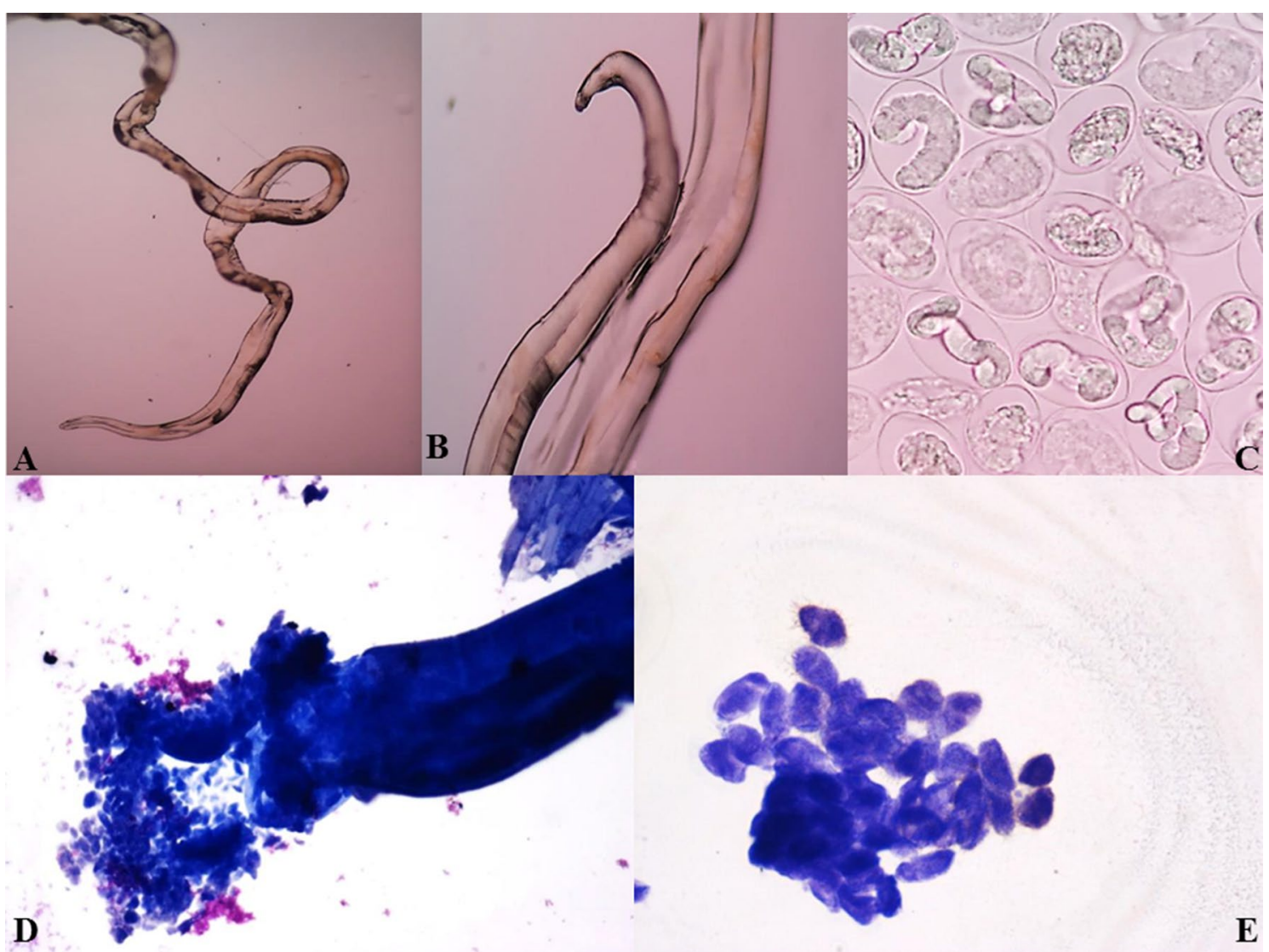

Fig. 2 A Wet mount showing one end of adult female worm; B wet mount of female worm other end intact; C wet mount after nick in intestine showed many embryoid forms of parasite coming out in thousands; $\mathbf{D}$ toluidine blue stain revealed adult gravid female worm intestine with embryoid forms coming out. E Embryoid forms in clusters (Tol Blue, $\times 40$ )

aspirate. Our case is an addition to this list of rare occurrence of adult gravid female worm in breast. Also in the present case, the length of gravid female worm was $4.5 \mathrm{~cm}$ (Intact worm).

Adult female worms of the two above mentioned species cannot be distinguished though adult male worms show minor differences. Species diagnosis thereby is made on the basis of morphology of the microfilaria $[1,4]$. The microfilaria of $W$. bancrofti is larger in size and possesses smooth body curve, its body nuclei are well-defined, discrete, round and uniform in size compared to that of $B$. malayi, which is smaller in size, possesses secondary kinks and blurred and intermingled nuclei. Tail tapers to a delicate point with absent terminal nucleus in $W$. bancrofti whereas later it is more bulbous and has two distinct terminal nuclei. However, differentiation between these two nematodes is not clinically important as the mode of treatment remains same $[2,4]$.

The methods of detection are demonstrating the microfilariae, adult worm, circulating filarial antigen (CFA) and ultrasound with or without color doppler demonstrating the filarial dance sign [2] We had radiological, cytological and histopathological investigations for correlation. Filariasis can be cured by administration of Diethylcarbamazine citrate (DEC) [2].

\section{Conclusion}

Our case report is to increase awareness of filariasis in tropical countries such as India where it's endemic. Filariasis should be considered as a differential diagnosis in subcutaneous lumps. Careful clinical, radiological 


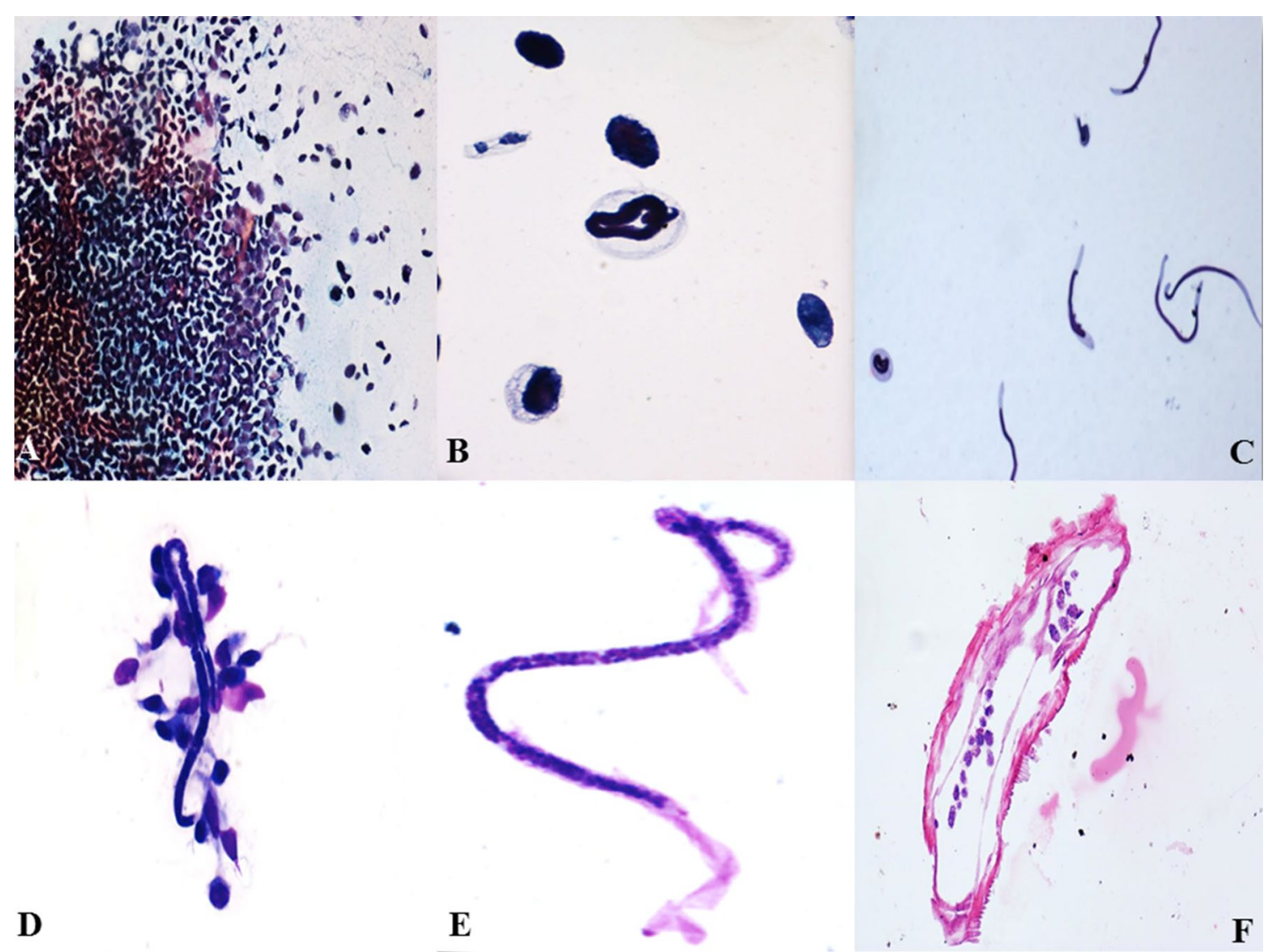

Fig. 3 A Microscopy showed many embryoid forms (PAP, $\times 10)$; B many coiled microfilariae and embryoid forms seen (PAP, $\times 40)$; C uncoiled sheathed microfilariae with tail end being free of nuclei. D Granulomatous reaction to filarial worm along with few lymphocytes, polymorphs and histiocytes along with a coiled microfilariae (Geimsa, $\times 10)$; $\mathbf{E}$ microfilaria with sheath and tail free of nuclei (Geimsa, $\times 40)$; $\mathbf{F}$ cell block preparation showing adult worm with many embryoid forms within intestinal cavity $(H \& E, \times 40)$

and cytological correlation is very important in prompt recognition of the disease and institution of specific treatment.

\section{Additional file}

Additional file 1. Microscopy showing the parasite with numerous embryoid forms comming out.

\section{Authors' contributions}

ST carried out concepts and design, literature search, participated in clinical study, data acquisition, data analysis and manuscript preparation and will stand as guarantor also. KK carried out concepts and design, literature search, manuscript review. RP participated in clinical study, data acquisition and manuscript review. SS and PK carried out literature search, clinical study and data acquisition. All authors read and approved the final manuscript.

\section{Acknowledgements}

NIL, no medical writer was involved.

\section{Competing interests}

The authors declare that they have no competing interests.

\section{Availability of data and materials}

All the data regarding the findings are available within the manuscript. Video link is available as Additional file 1.

\section{Consent to publish}

Written informed consent was obtained from the patient for publication of this case report and any accompanying images.

\section{Ethical clearance and consent to participate}

Permission for publication of this case was obtained from Institutional Ethics Committee.

Funding

Nil (for all authors).

\section{Publisher's Note}

Springer Nature remains neutral with regard to jurisdictional claims in published maps and institutional affiliations.

Received: 28 March 2017 Accepted: 29 July 2017

Published online: 16 August 2017 


\section{References}

1. Chatterjee KD. Phylum Nemathelminthes: Class Nematoda. In: Chatterjee KD, editor. Parasitology in relation to clinical medicine. 13th ed. Calcutta: CBS Publishers and distributors; 1980. p. 237-8.

2. Park K. Epidemiology of communicable diseases. In: Park K, editor. Park's text book of preventive and social medicine. 23rd ed. New Delhi: Bhanot publishers; 2015. p. 270-6

3. Chakrabarti I, Das V, Halder B, Giri A. Adult filarial worm in the aspirate from a breast lump mimicking fibroadenosis. Trop Parasitol. 2011;1:129-31.

4. Afrose R, Alam MF, Ahmad SS, Naim M. Filarial abscess: aspiration of adult gravid female worm from submandibular region, an unusual presentation. J Cytol. 2017;34:66-8.

5. Santosh T, Manoj KP, Atanu KB, Anita C. Microfilariae in a bone marrow aspirate. BMC Res Notes. 2016;9:256-9.

6. Mitra SK, Mishra RK, Verma P. Cytological diagnosis of microfilariae in filariasis endemic areas of eastern Uttar Pradesh. J Cytol. 2009;26:11-4
7. Arora VK, Sen B, Dev G, Bhatia A. Fine needle aspiration identification of the adult worm of Brugia malayi and its ovarian fragment from an epitrochlear lymph node. Acta Cytol. 1993;37:437-8.

8. Pandit AA, Shah RK, Shenoy SG. Adult filarial worm in a fine needle aspirate of a soft tissue swelling. Acta Cytol. 1997;41:944-6.

9. Azad K, Arora R, Gupta K, Sharma U. Lymphatic filariasis: aspiration of adult gravid female worm from a soft tissue swelling. J Cytol. 2010;27:156-7.

10. Satpathi S, Patnaik J, Rath PK, Panda RR, Behera PK, Satpathi P. Adult filarial worm by fine needle aspiration cytology of breast lumps. Acta Cytol. 2010;54(5):10857.

11. Pal S, Bose K. Microfilaria in fine needle aspiration cytology of breast lump: an unusual finding. J Health Spec. 2015;3:235-7.

12. Naorem GS, Leena C. Filariasis of the breast, diagnosed by fine needle aspiration cytology. Ann Saudi Med. 2009;29(5):414-5.

\section{Submit your next manuscript to BioMed Central and we will help you at every step:}

- We accept pre-submission inquiries

- Our selector tool helps you to find the most relevant journal

- We provide round the clock customer support

- Convenient online submission

- Thorough peer review

- Inclusion in PubMed and all major indexing services

- Maximum visibility for your research

Submit your manuscript at www.biomedcentral com/submit

() Biomed Central 